Article

\title{
A Compact Band-Pass Filter with High Selectivity and Second Harmonic Suppression
}

\author{
Ramona Cosmina Hadarig *, Maria Elena de Cos Gomez and Fernando Las-Heras \\ Signal Theory and Communications Area, Department of Electrical Engineering, University of \\ Oviedo, Multi-Purpose Building, Module 8, Gijón 33203 (Asturias), Spain; \\ E-Mails: medecos@tsc.uniovi.es (M.E.C.G.); flasheras@tsc.uniovi.es (F.L.-H.) \\ * Author to whom correspondence should be addressed; E-Mail: rhadarig@ tsc.uniovi.es.
}

Received: 3 October 2013; in revised form: 6 November 2013 / Accepted: 19 November 2013 / Published: 3 December 2013

\begin{abstract}
The design of a novel band-pass filter with narrow-band features based on an electromagnetic resonator at $6.4 \mathrm{GHz}$ is presented. A prototype is manufactured and characterized in terms of transmission and reflection coefficient. The selective passband and suppression of the second harmonic make the filter suitable to be used in a $\mathrm{C}$ band frequency range for radar systems and satellite/terrestrial applications. To avoid substantial interference for this kind of applications, passive components with narrow band features and small dimensions are required. Between $3.6 \mathrm{GHz}$ and $4.2 \mathrm{GHz}$ the band-pass filter with harmonic suppression should have an attenuation of at least $35 \mathrm{~dB}$, whereas for a passband, less than $10 \%$ is sufficient.
\end{abstract}

Keywords: band-pass filter; artificial magnetic conductor; dispersion diagram; second harmonic suppression; transmission coefficient

\section{Introduction}

In recent years, emerging applications have continued to challenge radio frequency (RF)/microwave filters' designers with stringent simultaneous requirements such as high performance, light weight, low cost and miniaturization. As the electromagnetic spectrum is limited and has to be shared, small sized band-pass filters with narrow frequency response and high selectivity are used to confine the signals within assigned spectral limits and to reject the noise and interferences from adjacent channels. 
To minimize the filter size, a practical strategy is to reduce the resonator circuit by modifying its physical structures [1-7]. Starting from the conventional parallel coupled band-pass filter [8-11] which has a simple synthesis procedure, and ending with U-shape resonators and open loops [12,13], hairpin filters [14] has helped progress in size reduction. However, with the rapid evolution of modern communication systems [15], the sizes of these resonators are still not small enough to be used.

In this work, a novel low thickness band-pass filter based on a simple and compact size electromagnetic resonator without vias is presented. The novelty of this contribution relies on taking advantage of the predicted electromagnetic band-gap (EBG) properties of a resonator unit-cell with improved performance (by means of its dispersion diagram) to achieve the intended band-pass filter behavior. Moreover, the filter exhibits a narrow passband, high out-of-band rejection level, and second harmonic suppression. The paper is organized as follows. Section 2 outlines the study of the unit-cell resonator in terms of dispersion diagram. In Section 3, the design of the filter is presented based on the unit-cell resonator. Also, the possibility of suppressing of the second harmonic is discussed. Two filters are manufactured and measurements concerning the transmission coefficient are provided to show their performance results.

\section{Resonant Element Design}

The first step in the design of the band-pass filter (henceforth referred to as BPF) is the design of the resonant element. In [16], the resonant element-replicated to model an infinite resonant structure - is characterized as an Artificial Magnetic Conductor (AMC) material [17-20] and the in-phase reflection property was studied. This feature enables efficient radiation for antennas placed closed to the periodic structure. In this contribution the resonant structure is seen from another point of view: as a material that has the possibility to block the propagation of electromagnetic waves in certain frequency bands and guide them in a desired direction [i.e., electromagnetic band-gap (EBG)].

EBG structures [21,22] exhibit allowed and forbidden bands of modes' propagation and can be characterized by the dispersion diagram. The dispersion diagram for a unit-cell of period $\mathrm{W}$ will show the relation between the wave number and frequency, giving information about the propagating modes and band-gaps that can potentially exist between such modes [23,24]. The eigenmode solver of High Frequency Structural Simulator (HFSS) together with proper boundary conditions along the sides of the unit-cell (resembling an infinite structure) is used in order to determine the dispersion diagram of the structure (see Figure 1a). Due to symmetry of the unit-cell, the dispersion diagram is computed along the lines connecting the $\mathrm{R}, \mathrm{X}$ and $\mathrm{M}$ points, to form the irreducible Brillouin triangle. Thus the dispersion analysis of periodic structures is reduced to find only the propagation modes in the direction of the vectors of the irreducible Brillouin triangle. The dispersion characteristics, i.e., the position and width of the band-gap and the frequency of the propagating modes are primarily defined by the geometry of the unit-cell. ARLON25N with relative dielectric permittivity 3.28 , loss tangent less than 0.0025 and a thickness of 0.762 (30 mils) is used as dielectric substrate. The unit-cell dimensions are $W \times W=11.52 \mathrm{~mm} \times 11.52 \mathrm{~mm}$ and its geometry exhibits four symmetry planes. The metallization thickness is $18 \mu \mathrm{m}$.

The dispersion diagram for three lowest modes is depicted in Figure 1b. The first mode propagates in the frequency range from 5 to $6.6 \mathrm{GHz}$, whereas the second mode propagates from 5 to $7 \mathrm{GHz}$. 
The resonance frequency takes place between the first and second mode, being around $6 \mathrm{GHz}$. Moreover, the bandgap is presented in a frequency range from 7 to $7.8 \mathrm{GHz}$. Within the bandgap, the electromagnetic waves cannot propagate at any direction in the EBG structure.

Figure 1. (a) Unit-cell resonator. The applied boundary conditions with the irreducible Brillouin triangle; and (b) Dispersion diagram of the periodic structure.
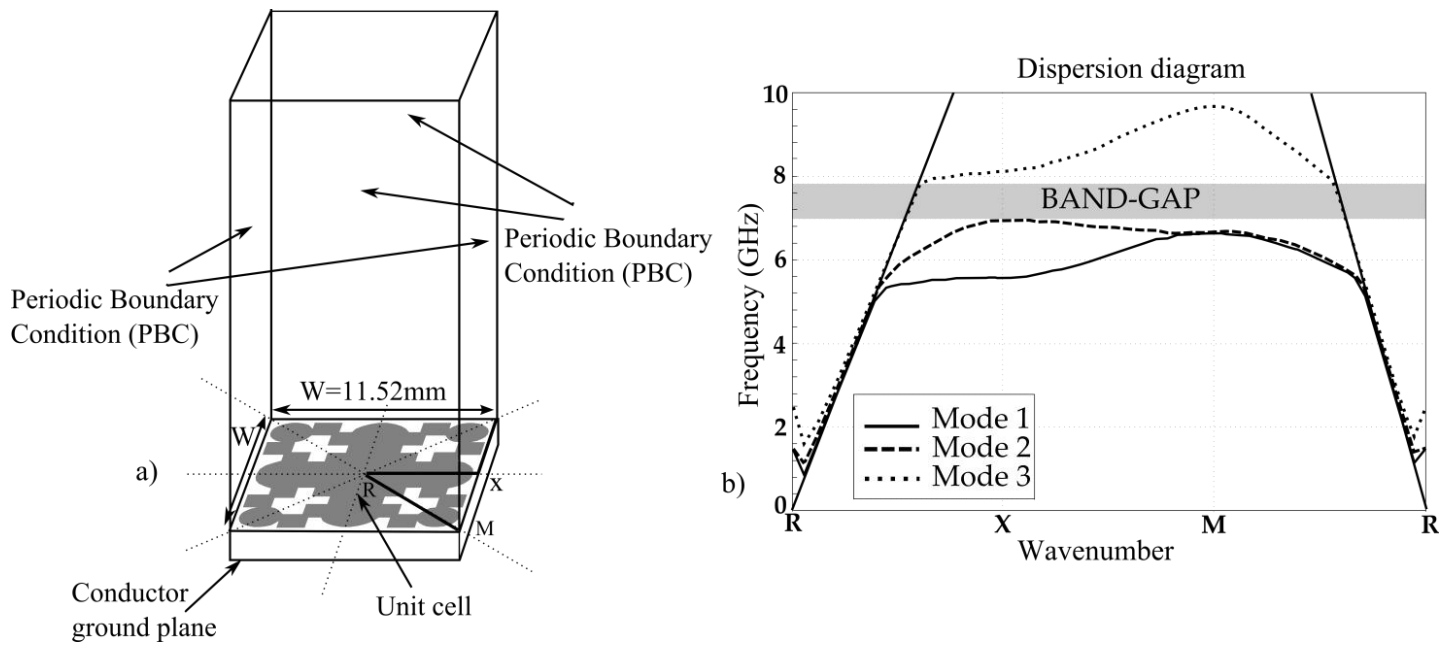

\section{Filter Design}

With the purpose of designing a band-pass filter having the same size as the unit-cell resonator, the propagation mode paths along the R-X-M triangle and predicted by the dispersion diagram could be followed. The frequency of the modes propagating along the edges of the Brillouin triangle have to be taken into account to define the filter passband, whereas the band-gap can be used to achieve the filter stopband. The computed dispersion diagram shows the propagation of the first mode in the frequency range from 5 to $6.6 \mathrm{GHz}$. In the present work, only the (M-R) region and part of the (X-M) region from the dispersion diagram were considered due to the fact that the authors' goal was to obtain a selective band-pass filter.

The distance between the metallization edge and the unit-cell edge influences the band-gap position. More precisely when the mentioned distance increases, the band-gap shifts to a higher frequency band whereas its width increases. The variation of the $a 2$ and $a 3$ parameters (see Figure 2) has the following effect: as $a 2$ and $a 3$ increase the band-gap shifts to a lower frequency band whereas the width of the band-gap increases. When $a 1$ and $a 4$ parameters decrease, meaning that the whole unit-cell size decreases, the band-gap shifts to a higher frequency band and its width increases. The thickness of the dielectric substrate also has an influence on the band-gap position. Increasing the thickness, the band-gap shifts to a lower frequency band and in the same time its width increases.

The filter consists of a unit-cell resonator and two narrow lines coupled to the resonator. Each narrow line has a width of $0.1 \mathrm{~mm}$ and a length of $11.52 \mathrm{~mm}$. The two narrow lines are placed symmetrically with respect to the unit-cell resonator. The gap between the coupling narrow line and unit-cell resonator is $0.1 \mathrm{~mm}$. The filter is excited by a pair of non-orthogonal input/output $50 \Omega$ microstrip feeding lines of $1.8 \mathrm{~mm}$ width and is printed on an ARLON25N substrate with a thickness 
of 30 mils, relative dielectric permittivity of 3.28, cooper thickness $18 \mu \mathrm{m}$ and loss tangent 0.0025 . The layout of the filter in $6.4 \mathrm{GHz}$ frequency band is presented in Figure 2.

Figure 2. Layout of the band-pass filter (BPF) with its characteristic circuit model.

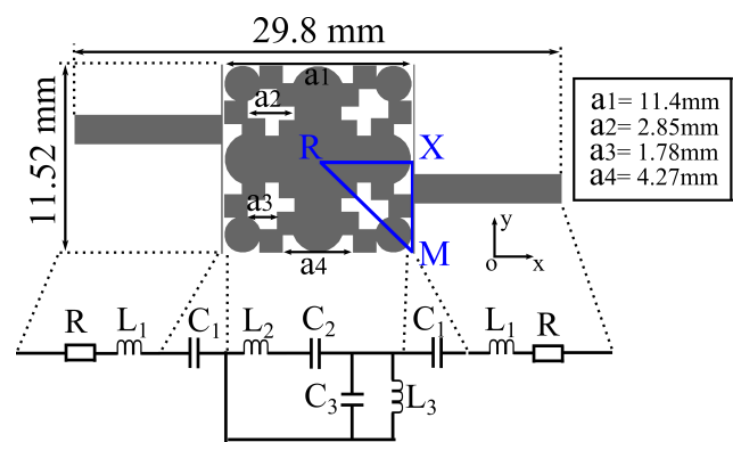

In order to determine the characteristics of the BPF, two approaches could be followed. The first one is to model the BPF using its equivalent circuit (or at least a simplified version) as can be seen in Figure 2. The resonator unit-cell can be model based on transmission line theory [25] providing that the unit-cell size is electrically small enough. The presented unit-cell is $\lambda_{0} / 5$ so it can be considered not so small and being at the limit of application of such a model. In any case the model would comprise a series connection $\left(\mathrm{L}_{2}\right.$ and $\left.\mathrm{C}_{2}\right)$ in parallel with the equivalent impedance of the parallel $\mathrm{L}_{3}$ and $\mathrm{C}_{3}$ components. In series with the mentioned circuit the capacitance $\mathrm{C}_{1}$ (formed between the resonator and each narrow coupling line) and $\mathrm{L}_{1}$ and $\mathrm{R}$ components (modeling the transmission line) are placed. The second approach consists in explaining the physical phenomena under the filter behavior. To achieve this aim the modes propagation in the structure should be explained based on dispersion diagram so the second approach is followed.

The dimensions of the filter are $29.8 \times 11.52 \times 0.762 \mathrm{~mm}^{3}\left(0.64 \lambda_{0} \times 0.25 \lambda_{0} \times 0.016 \lambda_{0}, \lambda_{0}\right.$ is the free space wavelength, $\lambda_{0}=47 \mathrm{~mm}$ at $6.4 \mathrm{GHz}$ ) considering the input/output feeding lines and $11.92 \times 11.52 \times 0.762 \mathrm{~mm}^{3}\left(0.25 \lambda_{0} \times 0.25 \lambda_{0} \times 0.016 \lambda_{0}\right)$ without the input/output feeding lines. From simulation results in Figure $3 \mathrm{a}$, the $3 \mathrm{~dB}$ passband of BPF without harmonic suppression goes from 6.25 to $6.62 \mathrm{GHz}$, meaning $5.75 \%$ fractional bandwidth at the center frequency $6.44 \mathrm{GHz}$. The minimum insertion loss is $1.7 \mathrm{~dB}$ whereas the maximum return loss value is greater than $17 \mathrm{~dB}$ (see Figure $3 b)$.

Figure 3. (a) Simulation vs. measurement: Transmission coefficient of the BPF; (b) Simulation $v s$. measurement: Reflection coefficient of the BPF.
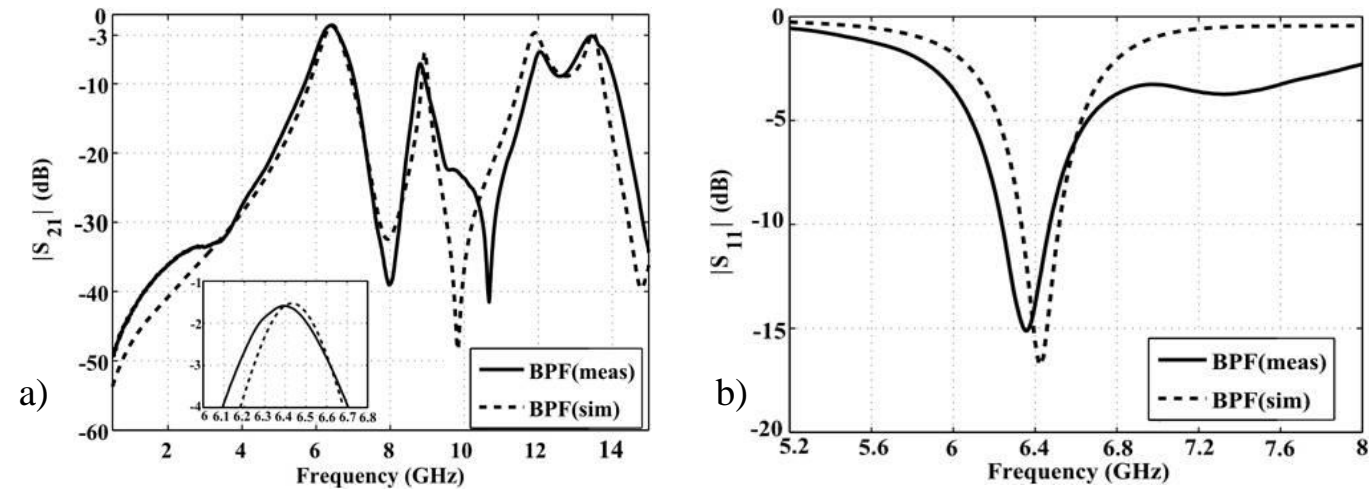
Taking into account the position of the feeding lines with respect to the unit-cell geometry, the propagation follows a quasi-diagonal path, which coincides with the (M-R) region from the dispersion diagram as being together with part of the (X-M) region. Furthermore, from the (M-R) region, as well as part of the $(\mathrm{X}-\mathrm{M})$ region of the dispersion diagram resulted in the first mode propagating in a frequency spectrum of between 6 and $6.6 \mathrm{GHz}$. This band corresponds to the electromagnetic wave propagation through the BPF geometry whereas from 6.94 to $7.9 \mathrm{GHz}$ the structure does not allow any mode propagation which corresponds to the stopband frequency region of the BPF.

In Table 1, the $3 \mathrm{~dB}$ bandwidth together with the quality factor are presented. In a band-pass filter, the overall width of the passband between the upper and lower $3 \mathrm{~dB}$ levels of the filter determines the quality factor $\mathrm{Q}$. The lower the value of the $\mathrm{Q}$ factor, the wider the bandwidth and, consequently, the higher the $\mathrm{Q}$ factor, the narrower and more selective the filter.

Table 1. Simulated band-pass filter quality factor.

\begin{tabular}{|c|c|c|c|c|c|c|c|c|}
\hline \multirow{2}{*}{ Prototype } & \multicolumn{2}{|c|}{$3 \mathrm{~dB}$} & \multirow{2}{*}{$f_{\mathrm{c}}$} & \multicolumn{2}{|c|}{$\mathrm{BW}(3 \mathrm{~dB})$} & \multirow{2}{*}{ Q } & \multirow{2}{*}{$\begin{array}{c}\text { Size } \\
(\mathrm{mm} \times \mathrm{mm})\end{array}$} & \multirow{2}{*}{$\begin{array}{c}\text { Size } \\
(\mathrm{mm} \times \mathrm{mm})\end{array}$} \\
\hline & $f_{\text {low }}(\mathrm{GHz})$ & $f_{\text {high }}(\mathrm{GHz})$ & & $\mathrm{GHz}$ & $\%$ & & & \\
\hline BPF & 6.25 & 6.62 & 6.44 & 0.37 & 5.57 & 17.40 & $29.80 \times 11.52 *$ & $11.92 \times 11.52$ \\
\hline 3-cells-oy BPF & 6.45 & 6.61 & 6.52 & 0.16 & 2.45 & 40.75 & $29.80 \times 34.56 *$ & $11.92 \times 34.56$ \\
\hline 3-cells-ox BPF & 6.55 & 6.67 & 6.62 & 0.12 & 1.81 & 55.16 & $52.84 \times 11.52 *$ & $34.96 \times 11.52$ \\
\hline Square BPF & 6.13 & 7.30 & 6.70 & 1.17 & 17.4 & 5.72 & $29.80 \times 11.52 *$ & $11.92 \times 11.52$ \\
\hline
\end{tabular}

According to the analysis shown in Table 1, if three resonators are cascaded in the OY direction (henceforth referred to as 3-cells-oy BPF) the $3 \mathrm{~dB}$ passband goes from 6.45 to $6.61 \mathrm{GHz}$, meaning $2.45 \%$ fractional bandwidth at the center frequency $6.52 \mathrm{GHz}$, whereas in the OX direction (filter henceforth referred to as 3-cells-ox BPF) the $3 \mathrm{~dB}$ passband goes from 6.55 to $6.67 \mathrm{GHz}$, meaning $1.8 \%$ fractional bandwidth at the center frequency $6.62 \mathrm{GHz}$. Moreover, using three cells in the direction of the current flow, the filter becomes more selective (see Figure 4a). The increment in the number of unit-cells in the OY direction has an influence only in the passband of the filter, which becomes narrower; meanwhile the slope in the stop bands remains the same. The benefit of the novel BPF over the square shaped resonator BPF is a quality factor three times greater. Figure $4 \mathrm{~b}$ shows that the return loss increases with the number of unit-cells.

Figure 4. (a) S21 simulation results; and (b) S11 simulation results.

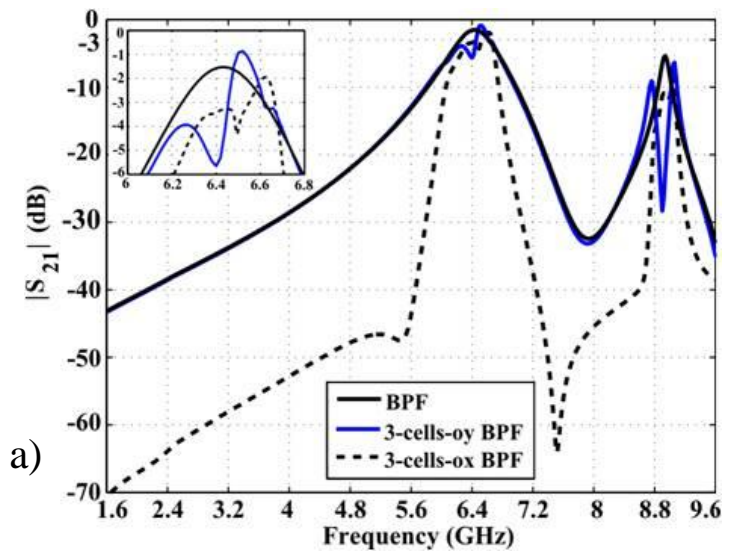

b)

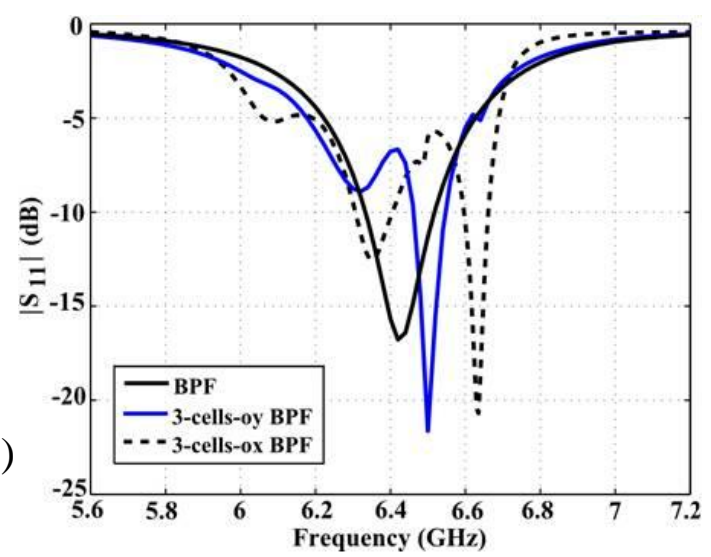


In order to suppress the second harmonic, several techniques have been reported in literature. In [26] two quarter wavelength open ended stubs are attached at the edges of the resonators in the main coupling path in order to have harmonic suppression, but this implies additional circuit elements against compact filter design. Another interesting alternative, such as using a continuous modulation in the coupled section of the filter [27,28] and using Koch fractal geometry [29], have also been considered, but both are time consuming due to the need of many parameters optimization. In this contribution, defected ground structures (DGS) are used to act as a low-pass filter. The slots are placed in the ground plane, directly under the input/output feeding lines [30].

The dimensions of the slots were chosen as $c=6.6 \mathrm{~mm}, d=5 \mathrm{~mm}, f=1.3 \mathrm{~mm}, g=0.4 \mathrm{~mm}$, $l=4.8 \mathrm{~mm}, m=4.4 \mathrm{~mm}, n=1.3 \mathrm{~mm}, x=1.6 \mathrm{~mm}, y=1.9 \mathrm{~mm}$ (see Figure 5a). The conductor strip of the microstrip line on the top plane has a width of $1.8 \mathrm{~mm}$, corresponding to $50 \Omega$ characteristic impedance.

From simulation results in Figure 5b, the DGS structure under the microstrip transmission line exhibits a $3 \mathrm{~dB}$ cutoff frequency at $7.15 \mathrm{GHz}$ and a center frequency of the stop band at $8.25 \mathrm{GHz}$ with a maximum attenuation of $33 \mathrm{~dB}$.

Figure 5. (a) Topology of defected ground structures (DGS) section (bottom view); and (b) transmission coefficient of DGS section.

a)

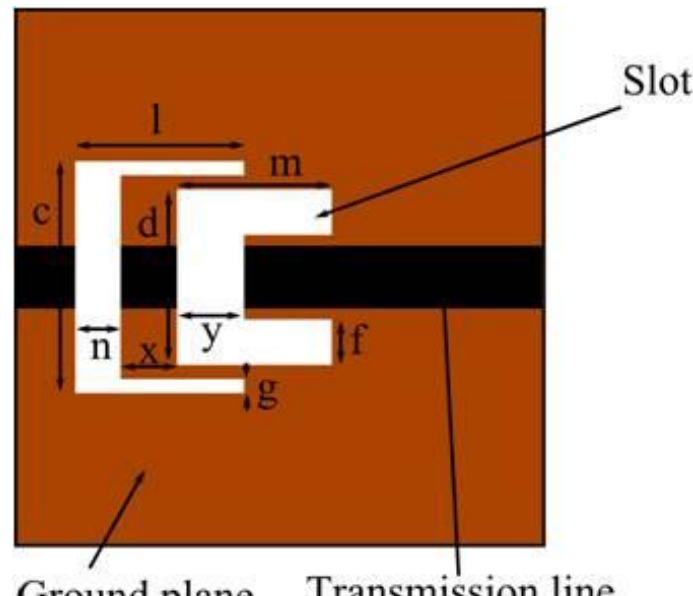

b)

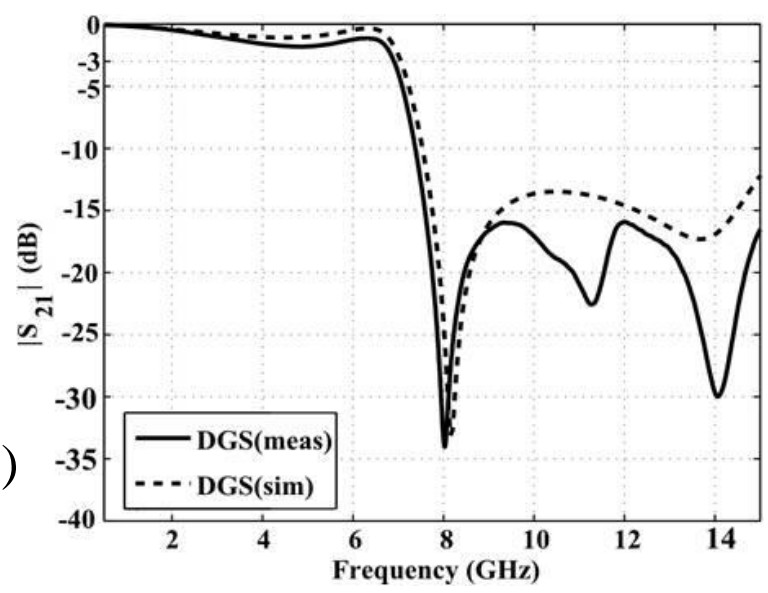

The dimensions of the slots placed in the ground plane influence the $3 \mathrm{~dB}$ cutoff frequency and the attenuation. Figure 6 shows the parametric study of the most important parameters " $x$ ", "l", " $m$ " and " $c$ ". Only one parameter is changed at a time during the analysis. By increasing the " $x$ " parameter, the $3 \mathrm{~dB}$ cutoff frequency decreases whereas the attenuation is almost the same at $8.25 \mathrm{GHz}$. The " $l$ " parameter controls both the attenuation at the center frequency of the stopband and the $3 \mathrm{~dB}$ cutoff frequency. On decreasing " $l$ ", the center frequency of the stopband, the attenuation and the $3 \mathrm{~dB}$ cutoff frequency increase. The parameters " $c$ " and " $m$ " influence only the $3 \mathrm{~dB}$ cutoff frequency. The $3 \mathrm{~dB}$ cutoff frequency decreases when the parameters " $c$ " and " $m$ " decrease. 
Figure 6. Parametric analysis of the DGS.
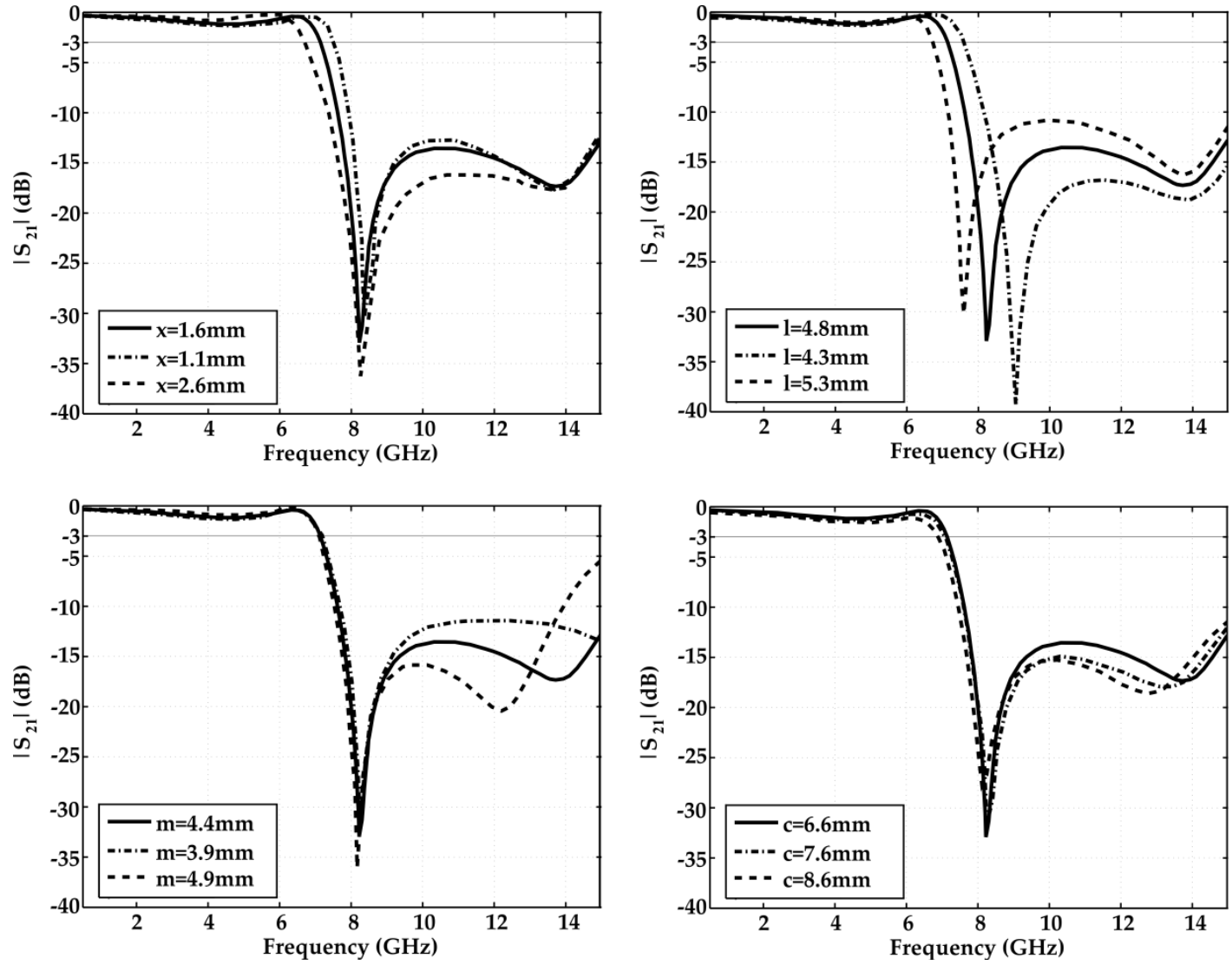

\section{Results}

Prototypes of the band-pass filter with second harmonic suppression (henceforth referred to as BPF-DGS) and without harmonic suppression using one unit-cell resonator, have been manufactured using laser micromachining (see Figure 7).

The results of measured transmission coefficient for the BPF-DGS and BPF prototypes are depicted in Figure 8a. The measured $3 \mathrm{~dB}$ bandwidth goes from 6.16 to $6.62 \mathrm{GHz}$, signifying $460 \mathrm{MHz}(7.18 \%)$ for the BPF prototype. There is good agreement between measurement and simulation results for the filter without harmonic suppression.

Regarding the BPF-DGS prototype, a $3 \mathrm{~dB}$ passband of $210 \mathrm{MHz}(3.32 \%)$ at the center frequency $6.32 \mathrm{GHz}$ is obtained in simulation whereas, in measurements, $175 \mathrm{MHz}(2.76 \%)$ passband at $6.33 \mathrm{GHz}$ resulted. In the stopband regions some slightly differences between measurement and simulation can be observed. The fact that commercial MoM software considers infinite extension of the dielectric substrate, together with manufacturing process tolerances and cables' and connectors' losses, explains the differences in the stopband region. Nevertheless, the simulations and measurement results are in good agreement and they meet the application requirements in the $\mathrm{C}$ band range. The filter with DGS exhibits approximately 50\% less pass bandwidth than the BPF without harmonic suppression because of the reduced coupling generated. 
Figure 7. Manufactured prototype band-pass filter with second harmonic suppression (BPF-DGS) (a) top view; (b) bottom view; and (c) cross-section view.

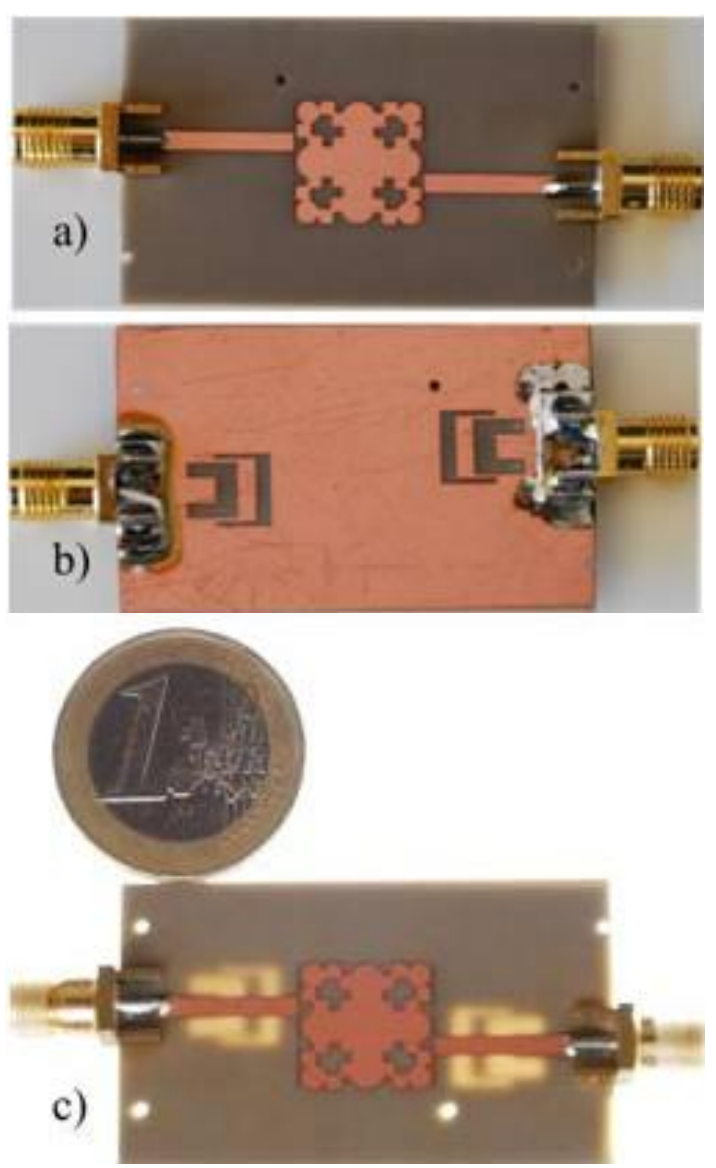

Figure 8. (a) S21 simulation and measurement results; and (b) S11 simulation and measurement results.
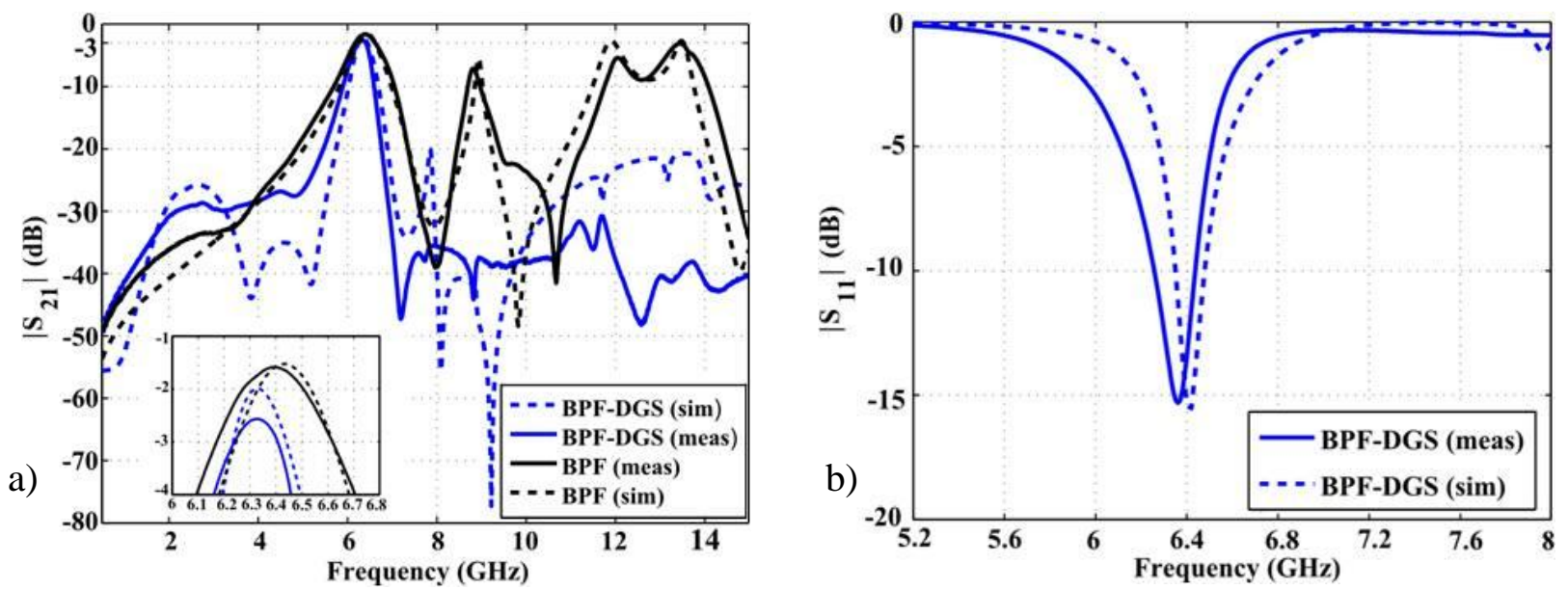

The absence of multilayer substrates and vias make the filters suitable to be used not only in satellite/terrestrial communication applications, but also in wearable applications where the prototypes could be shape adapted and bended. From Table 2, it can be easily seen that the size of the proposed BPF is minimized compared to band-pass filters with similar performance and substrate as used in [31-34], whereas the BPF-DGS shows a higher quality factor. 
Table 2. Comparison with other band-pass filters.

\begin{tabular}{|c|c|c|c|c|c|c|c|c|}
\hline \multirow{2}{*}{ Prototype } & \multicolumn{2}{|c|}{$3 \mathbf{d B}$} & \multirow{2}{*}{$f_{\mathrm{c}}$} & \multicolumn{2}{|c|}{ BW(3 dB) } & \multirow{2}{*}{$\mathbf{Q}$} & \multirow{2}{*}{$\begin{array}{c}\text { Size } \\
(\mathbf{m m} \times \mathbf{m m})\end{array}$} & \multirow{2}{*}{$\begin{array}{l}\text { Size } \lambda \text {-wavelength } \\
\text { at the corresp. } f_{\mathrm{c}}\end{array}$} \\
\hline & $f_{\text {low }}(\mathbf{G H z})$ & $f_{\text {high }}(\mathbf{G H z})$ & & GHz & $\%$ & & & \\
\hline \multirow{2}{*}{ BPF } & \multirow{2}{*}{6.25} & \multirow{2}{*}{6.62} & \multirow{2}{*}{6.44} & \multirow{2}{*}{0.37} & \multirow{2}{*}{5.75} & \multirow{2}{*}{17.40} & $29.8 \times 11.52 *$ & $0.63 \lambda \times 0.25 \lambda *$ \\
\hline & & & & & & & $11.92 \times 11.52$ & $0.25 \lambda \times 0.25 \lambda$ \\
\hline BPF-DGS & 6.23 & 6.40 & 6.33 & 0.17 & 2.76 & 36.38 & $29.8 \times 11.52$ & $0.63 \lambda \times 0.25 \lambda$ \\
\hline [31] & 5.46 & 5.84 & 5.65 & 0.38 & 6.72 & 14.80 & $46.2 \times 11.5$ & $0.87 \lambda \times 0.21 \lambda$ \\
\hline [35] & 5.58 & 5.83 & 5.71 & 0.25 & 4.46 & 22.80 & $40 \times 10$ & $0.76 \lambda \times 0.19 \lambda$ \\
\hline [35] & 5.39 & 6.02 & 5.71 & 0.63 & 11.14 & 9.06 & $40 \times 10$ & $0.76 \lambda \times 0.19 \lambda$ \\
\hline [36] & 5.88 & 6.12 & 6 & 0.24 & 4.05 & 25 & $15 \times 13$ & $0.3 \lambda \times 0.26 \lambda$ \\
\hline [32] & 6.63 & 6.96 & 6.8 & 0.33 & 4.9 & 20.6 & $20 \times 22$ & $0.45 \lambda \times 0.5 \lambda$ \\
\hline [33] & 5.09 & 5.35 & 5.25 & 0.26 & 4.9 & 20.2 & $45 \times 14$ & $0.79 \lambda \times 0.25 \lambda$ \\
\hline [34] & 5.14 & 5.38 & 5.25 & 0.24 & 4.57 & 21.8 & $19.8 \times 17.9$ & $0.35 \lambda \times 0.31 \lambda$ \\
\hline [37] & 4.78 & 5.61 & 5.2 & 0.83 & 16 & 6.26 & $26.3 \times 9.9$ & $0.45 \lambda \times 0.17 \lambda$ \\
\hline [38] & 5.54 & 5.86 & 5.7 & 0.32 & 5.6 & 17.81 & $26 \times 8$ & $0.5 \lambda \times 0.15 \lambda$ \\
\hline [39] & 1.36 & 1.49 & 1.42 & 0.13 & 9 & 10.9 & $22.14 \times 5.08$ & $0.1 \lambda \times 0.023 \lambda$ \\
\hline [40] & 2.84 & 4.2 & 3.4 & 1.36 & 40 & 2.5 & $20 \times 15$ & $0.22 \lambda \times 0.17 \lambda$ \\
\hline
\end{tabular}

The miniaturized BPF-DGS is demonstrated at $6.33 \mathrm{GHz}$, which is a higher frequency than the reported filter in [35]. If the proposed filter would be made to operate in the same frequency band as in [35], the filter would have a smaller size compared to [35].

In [37], the proposed filter renders a quality factor of 6.26 , which is approximately three or six times lower compared to 17.4 of the BPF and 36.38 of the BPF-DGS. In [39], the upper conducting layer of the filter is connected through the bottom ground plane using vias. Even though in [39] a $0.1 \lambda_{0} \times 0.023 \lambda_{0}$ miniaturized band-pass filter is shown, with a lower quality factor, it has the disadvantage of high cost and a difficult manufacture process due to the use of vias which are vulnerable to environmental influences such as being insufficiently plated through or filled with solder. This may cause the delamination or cracking of the vias.

\section{Conclusions}

The design of a frequency selective band-pass filter with small dimensions and second harmonic suppression using an electromagnetic resonator has been presented. A prototype has been manufactured at $6.4 \mathrm{GHz}$ and characterized based on transmission loss measurements. Second harmonic suppression was obtained using a DGS topology. The filter presents a high selectivity with a sharp passband to stop band transition. The compact size, low cost, simple fabrication and integration with other components in the system make it appropriate for satellite/terrestrial communication and wearable applications.

\section{Acknowledgments}

This work has been supported by the Ministerio de Ciencia e Innovación of Spain/FEDER under projects TEC2011-24492 (ISCAT) and CONSOLIDER-INGENIO CSD2008-00068 (TERASENSE), 
by the Gobierno del Principado de Asturias (PCTI)/FEDER-FSE under projects PC10-06 (FLEXANT), by grant BP10-039.

\section{Conflicts of Interest}

The authors declare no conflict of interest.

\section{References}

1. Kam, M.S.; Mo, T.; Xue, Q.; Chan, C.H. A compact bandpass filter with two tuning transmission zeros using a CMRC resonator. IEEE Trans. Microw. Theory Tech. 2005, 53, 895-900.

2. Hettstedt, F.; Lehmann, T.; Knoechel, R. Novel dual mode microstrip bandpass-filter. IEEE Microw. Mag. 2009, 10, 155-157.

3. Hsu, C.Y.; Chen, C.Y.; Chuang, H.R. Shunted-line stepped-impedance resonator. IEEE Microw. Mag. 2012, 13, 34-48.

4. Boutejdar, A.; Omar, A.; Burte, E. Design and optimization of new compact tunable 2.4-GHz band pass filter using coupled $\lambda / 2$ microstrip open loop resonators and memes-switch technique. Microw. Opt. Technol. Lett. 2013, 55, 2444-2450.

5. Boutejdar, A.; Al Sharkawy, M.; Omar, A.S. A simple transformation of improved WLAN band pass to low pass filter using defected ground structure (DGS), defected microstrip structure (DMS) and multilayer-technique. J. Microw. Optoelectron. Electromagn. Appl. 2013, 12, 111-130.

6. Boutejdar, A. An improvement of defected ground structure lowpass/bandpass filters using h-slot resonators and coupling matrix method. J. Microw. Optoelectron. Electromagn. Appl. 2011, 10, 295-307.

7. Boutejdar, A.; Omar, A.S.; Senst, A.; Batmanov, A.; Burte, E.; Mikuta, R. A New Design of a Tunable WLAN-Band Pass Filter Using a Combination of Varactor Device, RF-Choke and Hairpin-Slottet Ground Structure (SGS). In Proceedings of 41th European Microwave Conference, Microwave Integrated Circuits Conference (EuMC) 2011, Manchester, UK, 10-11 October 2011; pp: 506-509.

8. Matthaei, G.; Young, L.; Jones, E. Microwave Filters, Impedance Matching Networks, and Coupling Structures; Artech House: Boston, MA, USA, 1980.

9. Kuan, H.; Lin, Y.-L.; Yang, R.-Y.; Chang, Y.-C. A multilayered parallel coupled microstrip bandpass filter with embedded SIR cells to have a broad upper rejection band. IEEE Microw. Wirel. Comp. Lett. 2010, 20, 25-27.

10. Matthaei, G.L. Design of parallel-coupled resonator filters. IEEE Microw. Mag. 2007, 8, 78-87.

11. Swanson, D.G. Narrow-band microwave filter design. IEEE Microw. Mag. 2007, 8, 105-114.

12. Hong, J.S.; Lancaster, M.J. Coupling of microstrip square open loop resonators for cross-coupled planar microwave filters. IEEE Trans. Microw. Theory Tech. 1996, 44, 2099-2109.

13. Chen, Y.-M.; Chang, S.-F.; Chou, C.-Y.; Liu, K.-H. A reconfigurable bandpass-bandstop filter based on varactor-loaded closed-ring resonators. IEEE Microw. Mag. 2009, 10, 138-140.

14. Wang, H.; Chu, Q.-X. A narrow-band hairpin-comb two pole filter with source-load coupling. IEEE Trans. Microw. Theory Tech. 2010, 20, 372-374. 
15. Chen, C.-F.; Huang, T.-Y.; Wu, R.-B. Novel compact net-type resonators and their applications to microstrip bandpass filters. IEEE Trans. Microw. Theory Tech. 2006, 54, 755-762.

16. De Cos, M.E.; Álvarez, Y.; Hadarig, R.C.; Las-Heras, F. Novel SHF band uniplanar artificial magnetic conductor. IEEE Antennas Wirel. Propag. Lett. 2010, 9, 44-47.

17. Hadarig, R.C.; de Cos, M.E.; Las-Heras, F. Microstrip patch antenna bandwidth enhancement using AMC/EBG structures. Int. J. Antennas Propag. 2012, 2012, doi:10.1155/2012/843754.

18. Hadarig, R.C.; de Cos, M.E.; Las-Heras, F. Novel miniaturized artificial magnetic conductor. IEEE Antennas Wirel. Propag. Lett. 2013, 12, 174-177.

19. De Cos, M.E.; Las-Heras, F. Novel flexible artificial magnetic conductor. Int. J. Antennas Propag. 2012, 2012, doi:10.1155/2012/353821.

20. Mantash, M.; Tarot, A.C.; Collardey, S.; Mahdjoubi, K. Investigation of flexible textile antennas and amc reflectors. Int. J. Antennas Propag. 2012, 2012, doi:10.1155/2012/236505.

21. Yang, F.R.; Ma, K.P.; Qian, Y.; Itoh, T. A uniplanar compact photonic-bandgap (UC-PBG) structure and its applications for microwave circuits. IEEE Trans. Microw. Theory Tech. 1999, 47, 1509-1514.

22. Yang, F.; Rahmat-Samii, Y. Electromagnetic Band-Gap Structures in Antenna Engineering; Cambridge University Press: Cambridge, UK, 2008.

23. Oskouei, D.H.; Forooraghi, K.; Hakkak, M. Guided and leaky wave characteristics of periodic defected ground structures. Prog. Electromagn. Res. 2007, 73, 15-27.

24. Sievenpiper, D.; Zhang, L.; Broas, R.F.J.; Alexopolous, N.G.; Yablonovitch, E. High impedance electromagnetic surface with a forbidden frequency band. IEEE Trans. Microw. Theory Tech. 1999, 47, 2059-2074.

25. Caloz, C.; Itho, T. Electromagnetic Metamaterials: Transmission Line Theory and Microwave Applications; Wiley Interscience: New York, NY, USA, 2006.

26. Karthikeyan, S.; Kshetrimayum, R.S. Harmonic suppression of parallel coupled microstrip line bandpass filter using CSRR. Prog. Electromagn. Res. Lett. 2009, 7, 193-201.

27. Naser-Moghadasi, M.; Alamolhoda, M. Spurious response suppression in hairpin filter using DMS integrated in filter structure. Prog. Electromagn. Res. 2011, 18, 221-229.

28. Lopetegi, T.; Laso, M.A.A.G.; Hernández, J.; Bacaicoa, M.; Benito, D.; Garde, M.J.; Sorolla, M.; Guglielmi, M. New microstrip wiggly-line filters with spurious passband suppression. IEEE Trans. Microw. Theory Tech. 2001, 49, 1593-1598.

29. Kim, K.; Kingsley, N.D.; Morton, M.A.; Papapolymerou, J.; Tentzeris, M.M.; Yook, J.G.G. Fractal shaped microstrip coupled line band pass filters for suppression of 2 nd harmonic. IEEE Microw. Theory Tech. 2005, 53, 2943-2948.

30. Woo, D.; Lee, T.; Lee, J.; Pyo, C.; Choi, W. Novel U slot and V slot DGSs for bandstop filter with improved Q factor. IEEE Trans. Microw. Theory Tech. 2006, 54, 2840-2847.

31. $\mathrm{Su}, \mathrm{B}$;; Huang, R. $5.8 \mathrm{GHz}$ bandpass filter design using planar couple microstrip lines. Int. Conf. Commun. Circuits Syst. 2004, 2, 1204-1207.

32. Wu, H.-W.; Yang, R.-Y. A new quad-band bandpass filter using asymmetric stepped impedance resonators. IEEE Microw. Wirel. Comp. Lett. 2011, 21, 203-205.

33. Chen, F.-C.; Chu, Q.-X. Design of compact tri-band bandpass filters using assembled resonators. IEEE Trans. Microw. Theory Tech. 2009, 57, 165-171. 
34. Lee, C.H.; Chung, G.H.; Hsu, C.C. Balanced dual-band BPF with stub-loaded SIRs for common-mode suppression. IEEE Microw. Wirel. Comp. Lett. 2010, 20, 70-72.

35. Lugo, C.; Thompson, D.; Papapolymerou, J. Reconfigurable Bandpass Filter with Variable Bandwidth at 5.8 GHz Using a Capacitive Gap Variation Technique. In Proceedings of 33rd European Microwave Conference, Munich, Germany, 7-9 October 2003; pp: 923-926.

36. Dong, Y.; Wu, C.-T.M.; Itoh, T. Miniaturised multi-band substrate integrated waveguide filters using complementary split-ring resonators. IET Microw. Antennas Propag. 2012, 6, 611-620.

37. Cheng, C.-M.; Yang, C.-F. Develop quad-band (1.57/2.45/3.5/5.2 GHz) bandpass filters on the ceramic substrate. IEEE Microw. Wirel. Comp. Lett. 2010, 20, 268-270.

38. Chen, C.-Y.; Hsu, C.-Y. A simple and effective method for microstrip dual-band filters design. IEEE Microw. Wirel. Comp. Lett. 2006, 16, 246-248.

39. Lin, S.-C.; Wang, C.-H.; Chen, C.H. Novel patch-via-spiral resonators for the development of miniaturized bandpass filters with transmission zeros. IEEE Trans. Microw. Theory Tech. 2007, 55, 137-146.

40. Boutejdar, A.; Batmanov, A.; Machac, J.; Burte, E.; Omar, A.S. A New Transformation of Bandpass Filter to Bandstop Filter Using Multilayer-Technique and U-Defected Ground Structure (DGS). In Proceedings of 14th International Conference on Microwave Techniques, Prague, Czech Republic, 23-24 April 2008; pp. 1-4.

(C) 2013 by the authors; licensee MDPI, Basel, Switzerland. This article is an open access article distributed under the terms and conditions of the Creative Commons Attribution license (http://creativecommons.org/licenses/by/3.0/). 